\title{
Efficacy of a herbal toothpaste on patients with established gingivitis - a randomized controlled trial
}

\section{Eficácia de um dentifrício fitoterápico em pacientes com gengivite estabelecida - ensaio clínico aleatório}

\author{
Fabiana Ozaki* \\ Claudio Mendes Pannuti** \\ Ana Vitória Imbronito*** \\ Wellington Pessotti**** \\ Luciana Saraiva*** \\ Nivea Maria de Freitas*** \\ Graziella Ferrari* \\ Veronica Neto Cabral*
}

\begin{abstract}
The aim of this randomised, double blind controlled trial was to verify the efficacy of a herbal dentifrice on the reduction of plaque and gingivitis. Forty eight volunteers with established gingivitis were randomly assigned to either a test group (herbal dentifrice) or positive control group (dentifrice with triclosan and fluoride). The dentifrices were distributed in plain white tubes by an independent pharmacy, which revealed the contents of each tube only after the experimental period. Plaque and gingivitis assessments were carried out on baseline and after 28 days of product use. All examinations were conducted by the same calibrated investigator. Subjects were instructed to brush their teeth three times daily using their assigned dentifrice for 28 days. There was a significant reduction in plaque levels in both the test and control groups. However, there was no significant difference between the groups. A significant reduction in gingivitis was observed in both groups, although there was no significant difference between them. No adverse reactions were reported. The authors concluded that both dentifrices were effective in reducing plaque and gingivitis in subjects with established gingivitis.
\end{abstract}

DESCRIPTORS: Gingivitis; Plant preparations; Phytotherapy; Triclosan.

RESUMO: O objetivo deste ensaio clínico aleatório duplo-cego foi verificar a eficácia de um dentifrício fitoterápico na redução de placa e gengivite. Quarenta e oito voluntários com gengivite estabelecida foram aleatoriamente alocados aos grupos teste (dentifrício fitoterápico) e controle positivo (dentifrício com triclosan e flúor). Os dentifrícios foram distribuídos em tubos brancos por uma farmácia independente, que revelou o conteúdo de cada tubo apenas após o final do período experimental. A aferição de placa e gengivite foi conduzida por um único examinador, previamente calibrado, no início e após 28 dias de uso do produto. Os sujeitos da pesquisa foram orientados a escovar os dentes com o dentifrício de seu grupo três vezes ao dia, por 28 dias. Houve redução significativa na quantidade de placa nos grupos teste e controle. No entanto, não houve diferença significativa entre os grupos. Os dois grupos experimentais apresentaram redução significativa nos niveis de gengivite, porém não houve diferença significativa entre eles. Não foram observadas reações adversas. Os autores concluíram que os dois dentifrícios foram eficazes na redução de placa e gengivite em indivíduos com gengivite estabelecida.

DESCRITORES: Gengivite; Preparações de plantas; Fitoterapia; Triclosan.

\section{INTRODUCTION}

Self-performed mechanical plaque removal is an unquestioned method of controlling plaque and gingivitis ${ }^{4,8,14}$. However, toothbrushing and flossing are difficult tasks, and most of the patients are not able to completely remove plaque in all teeth surfaces ${ }^{11}$. Mechanical plaque control is also time-consuming, and some individuals may lack motivation for these procedures. In an effort to

\footnotetext{
* Private Practice, São Paulo, Brazil.

** Biodentistry Graduate Program; ****Undergraduate Student - School of Dentistry, Ibirapuera University.

*** Department of Periodontics, School of Dentistry, University of São Paulo.
} 
Ozaki F, Pannuti CM, Imbronito AV, Pessotti W, Saraiva L, Freitas NM, Ferrari G, Cabral VN. Efficacy of a herbal toothpaste on patients with established gingivitis - a randomized controlled trial. Braz Oral Res 2006;20(2):172-7.

improve the efficacy of mechanical tooth-cleaning procedures, antimicrobial agents have been added to dentifrices ${ }^{2,17}$.

One of the most effective agents for supragingival plaque control is chlorhexidine ${ }^{1,7,10}$. However, a significant reduction of its antiplaque potential may be observed when it is used in a toothpaste preparation ${ }^{5}$. Triclosan has also been incorporated into dentifrices, and some studies have demonstrated a significant reduction of plaque and gingivitis $^{9,15}$.

Interest in alternative mouthrinses and toothpastes based on plant extracts has increased recently. Among these herbal products, Parodontax ${ }^{\circledR}$ (GlaxoSmithKline, Middlesex, United Kingdom) has received great attention. It is composed of sodium bicarbonate, sodium fluoride $(1,400 \mathrm{ppm})$ and herbal ingredients: chamomile, which is supposed to have anti-inflammatory properties and to decrease gingival inflammation; echinacea, which is reputed to stimulate the immune response; sage and rhatany, which have anti-hemorrhagic properties; myrrh, claimed to be a natural anti-septic; and peppermint oil, which has analgesic, anti-septic and anti-inflammatory properties.

Some studies have reported that Parodontax ${ }^{\circledR}$ is able to significantly decrease plaque and gingivitis $^{24,25}$, while other publications showed no effectiveness of the dentifrice when compared to a control $^{16,18,20}$.

In many trials, study subjects receive dental prophylaxis and oral hygiene instructions prior to the commencement of the experiment. However, for the majority of the population, plaque removal is unsupervised, which leads to high scores of plaque accumulation and gingivitis. For a clearly evident effect of an antimicrobial agent to be proven, it should be demonstrated on established gingivitis subjects, which are representative of the vast majority of dentifrice users.

The aim of this study was to evaluate the efficacy of the Parodontax ${ }^{\circledR}$ dentifrice in the reduction of plaque and gingivitis in subjects with established gingivitis.

\section{MATERIALS AND METHODS}

Volunteers for this study were recruited in the Dental Clinic at the Associação Paulista de Cirurgiões Dentistas, in São Caetano (Brazil). They were admitted to the study if they met the following eligibility criteria: age $\geq 18$ years, a minimum of 15 teeth, good general health, a baseline
Plaque Score mean > 1.5 (Quigley, Hein ${ }^{19}, 1962$ as modified by Turesky et al. $\left.{ }^{23}, 1970\right)$ and presence of established gingivitis. Established gingivitis was defined as a baseline Löe, Silness ${ }^{13}$ (1963) Gingival Index mean $>1.0$. The plaque score mean and the Gingival index mean were based on inclusion criteria used by Binney et al. ${ }^{6}$ (1996) and Owens et al. ${ }^{17}$ (1997). Exclusion criteria were: presence of advanced periodontal disease, which was defined as presence of CPITN code 4 teeth $^{3}$, use of orthodontic appliances, use of antibiotics in the previous 3 months, continuous use of mouthrinses containing chemical agents in the previous 3 months, and a history of allergy to toothpastes or Parodontax.

Initially, 48 healthy subjects ( 20 males and 28 females), ranging in age from 18-69 years (mean age $33.19 \pm 13.57$ ) were considered eligible for the study. All subjects were given oral and written information about the study, and before entering the study, they signed a written informed consent. The study protocol was approved by the Ethics Committee of the Ibirapuera University. All procedures in this experiment were performed according to the ethical principles established by the Declaration of Helsinki.

The study was designed as a randomised, double blinded, parallel arm controlled trial. The subjects were randomly assigned to either the test or positive control group. The random allocation sequence was generated by one of the authors (C.M.P.), who used a random-number table. The random allocation sequence was concealed from the main investigator (F.O.) until the dentifrices were assigned to the participants. The main investigator was responsible for enrolling the subjects and assessing the study variables. Blinding and allocation concealment were controlled by the independent Pharmacy "Fórmula e Ação", which distributed the toothpastes in plain white tubes, identified as "group A" and "group B" tubes. All investigators and study subjects were unaware of the contents of each tube. The pharmacy revealed the contents of each tube only after the experimental period was over.

Volunteers in the test group received a toothpaste tube containing $90 \mathrm{~g}$ of Parodontax ${ }^{\circledR}$ denti- $^{-}$ frice (GlaxoSmithKline, Middlesex, United Kingdom) containing sodium bicarbonate, sodium fluoride 1,400 ppm, chamomile, echinacea, sage, rhatany, myrrh and peppermint oil. Subjects in the control group received a toothpaste tube containing 90 g of Colgate Total (Colgate-Palmolive Company, New York, United States of America), containing 
Ozaki F, Pannuti CM, Imbronito AV, Pessotti W, Saraiva L, Freitas NM, Ferrari G, Cabral VN. Efficacy of a herbal toothpaste on patients with established gingivitis - a randomized controlled trial. Braz Oral Res 2006;20(2):172-7.

$0.3 \%$ triclosan, $2 \%$ copolymer and $0.243 \%$ sodium fluoride. The control dentifrice was modified by "Fórmula e Ação" Pharmacy, to have its colour and taste similar to the Parodontax dentifrice.

No prophylaxis was undertaken prior to commencement of the study, and no attempt was made to modify the volunteers' oral hygiene habits. All participants used dental floss during the study. At baseline, the amount of plaque and gingival inflammation was measured on all teeth, at the buccal, mesial, distal and lingual aspects, with the exception of the third molars. The participants were stained for plaque using an erythrosine disclosing solution and cotton swabs. The amount of plaque was scored using the Turesky ${ }^{23}$ (1970) modification of the Quigley, Hein ${ }^{19}$ (1962) index. After that, gingival inflammation was recorded using the Gingival Index (GI) ${ }^{13}$. All measurements were conducted by the main investigator (F.O.), who was previously calibrated. For calibration, two measurements were performed with one-hour interval. Intra-examiner calibration was performed in 5 patients until an $80 \%$ agreement was obtained.

After scoring plaque and gingival inflammation, the subjects were instructed to brush with the assigned toothpaste 3 times a day. Rinsing with water after toothbrushing was not allowed, as well as using any other toothpaste or mouthrinse during the experimental period.

After 28 days, the subjects returned for another appointment, in which the amounts of plaque and gingival inflammation were scored again by the same investigator. To check for compliance, the participants were asked to return their assigned tubes, so that the investigators could verify the amount of dentifrice that was used. Volunteers were also asked about adverse events, such as taste disturbance, mucosal sensitivity etc.

Statistical analysis was performed using a statistics package (SPSS 11.0 for Windows). The subject was the unit of analysis. Plaque scores and Gingival Index scores were averaged on a persubject basis. Each participant had a whole-mouth average score for baseline and another for the 28day exam, presented separately for buccal/lingual aspects and mesial/distal aspects. The distribution of the variables was not normal, so group means were compared using the Mann-Whitney U test. Differences between baseline and the 28-day exam were evaluated using the Wilcoxon test. Groups were also compared regarding age by means of the Student's $t$ test, and association between group and sex was verified by means of the chi-square test. All statistical tests employed a level of significance of $\alpha=0.05$.

\section{RESULTS}

Forty-two (16 males and 26 females) of the initial 48 subjects completed the 28 -days study period. There were six dropouts throughout the trial. Four individuals were contacted but declared they were "too busy" or "didn't have time" to come to the 28day exam. They were examined and received a prophylaxis one or two weeks later, but data pertaining to these patients was not used in the statistical analysis. Two individuals declared they did not have interest in another appointment because they "have already received a dental prophylaxis".

The mean age in the test group $(\mathrm{n}=20)$ was $31.55 \pm 14.6$, and in the control group $(n=22)$ was $34.68 \pm 12.73$. There was no significant difference between groups according to age $(p=0.46)$, and there was no significant association between group and $\operatorname{sex}(p=0.23)$, which means that both groups were homogeneous.

At baseline, there was no significant difference in Plaque Scores between the two groups. After 28 days, the test group presented an average 19.9\% reduction in plaque at the buccal and lingual surfaces, whereas the control group showed an 18.3\% reduction (Table 1). At the proximal surfaces, a

TABLE 1 - Mean, median and comparison between groups according to the Plaque Index at buccal and lingual aspects.

\begin{tabular}{c|c|c|c|c}
\hline \hline & & Baseline & 28 days & p (W) \\
\hline \multirow{2}{*}{$\begin{array}{c}\text { Herbal toothpaste } \\
\mathrm{N}=20\end{array}$} & Mean $\pm \mathrm{SD}$ & $2.11 \pm 0.68$ & $1.69 \pm 0.64$ & \multirow{2}{*}{$0.033^{*}$} \\
\cline { 2 - 4 } & Median & 2.03 & 1.69 & \multirow{2}{*}{$0.001^{*}$} \\
\hline $\begin{array}{c}\text { Positive control } \\
\mathrm{N}=22\end{array}$ & Mean $\pm \mathrm{SD}$ & $2.13 \pm 0.60$ & $1.74 \pm 0.60$ & \\
\cline { 2 - 4 } & Median & 2.08 & 1.65 & \\
\hline \hline
\end{tabular}

*Significant at the 5\% level; W = Wilcoxon test; MW = Mann-Whitney test. 
Ozaki F, Pannuti CM, Imbronito AV, Pessotti W, Saraiva L, Freitas NM, Ferrari G, Cabral VN. Efficacy of a herbal toothpaste on patients with established gingivitis - a randomized controlled trial. Braz Oral Res 2006;20(2):172-7.

reduction of $19.6 \%$ and $15.4 \%$ was observed for test and control groups, respectively (Table 2). Both dentifrices produced a significant reduction in plaque scores. However, the difference between the groups was not statistically significant.

There was no significant difference in the Gingival Index between the groups at baseline. After 28 days, a mean $28.4 \%$ and $36.3 \%$ reduction in GI was observed in the test and control groups, respectively, at the buccal and lingual surfaces (Table 3). At the proximal surfaces, a decrease of $23.5 \%$ was observed in the test group, and a $32.5 \%$ reduction occurred in the control group (Table 4). In both groups a significant decrease in mean GI was observed, although there was no significant difference between the groups.

No adverse reactions were observed during the trial. None of the volunteers reported any se- rious reaction or discomfort related to the toothpastes.

\section{DISCUSSION}

Lately, there has been growing interest in natural products. Even though studies in animals and in vitro may show the antimicrobial properties of several of these products, there is no other way of knowing their real clinical effect without conducting a randomized clinical trial. Detergents and abrasives may alter the substantivity or the antimicrobial activity of active ingredients. The principal ingredients of Parodontax (chamomile, echinacea, sage, rhatany, myrrh and peppermint oil) have several medicinal properties. However, data pertaining to the substantivity of these products cannot be found in literature. It is important that clinical tri-

TABLE 2 - Mean, median and comparison between groups according to the Plaque Index at mesial and distal aspects.

\begin{tabular}{c|c|c|c|c}
\hline \hline & & Baseline & 28 days & $\mathrm{p}(\mathrm{W})$ \\
\hline \multirow{2}{*}{$\begin{array}{c}\text { Herbal toothpaste } \\
\mathrm{N}=20\end{array}$} & Mean $\pm \mathrm{SD}$ & $2.44 \pm 0.69$ & $1.96 \pm 0.53$ & \multirow{2}{*}{$0.018^{*}$} \\
\cline { 2 - 4 } & Median & 2.56 & 2.01 & \\
\hline \multirow{2}{*}{$\begin{array}{c}\text { Positive control } \\
\mathrm{N}=22\end{array}$} & Mean $\pm \mathrm{SD}$ & $2.40 \pm 0.59$ & $2.03 \pm 0.55$ & \multirow{2}{*}{$0.002^{*}$} \\
\cline { 2 - 4 } & Median & 2.47 & 1.94 & \\
\hline \hline
\end{tabular}

*Significant at the 5\% level; $\mathrm{W}=$ Wilcoxon test; $\mathrm{MW}=$ Mann-Whitney test.

TABLE 3 - Mean, median and comparison between groups according to the Gingival Index at buccal and lingual aspects.

\begin{tabular}{c|c|c|c|c}
\hline \hline & & Baseline & 28 days & $\mathrm{p}(\mathrm{W})$ \\
\hline \multirow{2}{*}{$\begin{array}{c}\text { Herbal toothpaste } \\
\mathrm{N}=20\end{array}$} & Mean $\pm \mathrm{SD}$ & $1.02 \pm 0.25$ & $0.73 \pm 0.37$ & \multirow{2}{*}{$0.012^{*}$} \\
\cline { 2 - 4 } & Median & 1.01 & 0.67 & \\
\hline \multirow{2}{*}{$\begin{array}{c}\text { Positive control } \\
\mathrm{N}=22\end{array}$} & Mean $\pm \mathrm{SD}$ & $1.02 \pm 0.28$ & $0.65 \pm 0.28$ & $0.001^{*}$ \\
\cline { 2 - 4 } & Median & 1.03 & 0.62 & \\
\hline \hline
\end{tabular}

*Significant at the $5 \%$ level; $\mathrm{W}=$ Wilcoxon test; MW = Mann-Whitney test.

TABLE 4 - Mean, median and comparison between groups according to the Gingival Index at mesial and distal aspects.

\begin{tabular}{c|c|c|c|c}
\hline \hline & & Baseline & 28 days & $\mathrm{p}(\mathrm{W})$ \\
\hline \multirow{2}{*}{$\begin{array}{c}\text { Herbal toothpaste } \\
\mathrm{N}=20\end{array}$} & Mean $\pm \mathrm{SD}$ & $1.19 \pm 0.27$ & $0.91 \pm 0.34$ & \multirow{2}{*}{$0.009^{*}$} \\
\cline { 2 - 4 } & Median & 1.18 & 0.89 & \\
\hline \multirow{2}{*}{$\begin{array}{c}\text { Positive control } \\
\mathrm{N}=22\end{array}$} & Mean $\pm \mathrm{SD}$ & $1.20 \pm 0.28$ & $0.81 \pm 0.25$ & \\
\cline { 2 - 4 } & Median & 1.15 & 0.83 & \\
\hline
\end{tabular}

*Significant at the 5\% level; $\mathrm{W}=$ Wilcoxon test; MW = Mann-Whitney test. 
Ozaki F, Pannuti CM, Imbronito AV, Pessotti W, Saraiva L, Freitas NM, Ferrari G, Cabral VN. Efficacy of a herbal toothpaste on patients with established gingivitis - a randomized controlled trial. Braz Oral Res 2006;20(2):172-7.

als verify the efficacy of any new product, instead of simply assuming that the product is efficient based on laboratory studies.

In a previous study ${ }^{18}$, Parodontax ${ }^{\circledR}$ was unable to promote a significant reduction in PI and GI when compared to a standard dentifrice containing only fluoride. One possible reason for the conflicting results obtained by either study is the population participating in each study. In the first experiment, the sample was composed of Dentistry students, who presented low PI and GI scores at baseline, which would have lessened the impact of any chemical agent on the levels of plaque and gingivitis. Comparatively, in the present study, all volunteers enrolled in the study started out with a large amount of established plaque and gingivitis. Prophylaxis and scaling were not carried out previous to the experimental phase, as in the studies by Lindhe et al. ${ }^{12}$ (1993), Triratana et al. ${ }^{22}$ (1993) and Triratana et al. ${ }^{21}$ (2002). The association of toothbrushing and the test dentifrice promoted reductions of 19\% in the Plaque Index and 23-28\% in the Gingival Index, while Triratana et al. ${ }^{21}$ (2002) observed reductions of $39.9 \%$ in PI and $25.7 \%$ in GI. Lindhe et al. ${ }^{12}$ (1993) observed an increase in the number of sites presenting a plaque score of

\section{REFERENCES}

1. Addy M. Chlorhexidine compared with other locally delivered antimicrobials. J Clin Periodontol 1986;13:957-64.

2. Addy M, Moran J, Wade W. Chemical plaque control in the prevention of gingivitis and periodontitis. In: Lang NP, Karring T. Proceedings of the First European Workshop on Periodontology. London: Quintessence Publishing; 1994. p. 244-57.

3. Ainamo J, Barmes D, Beagrie G, Cutress T, Martin J, SardoInfirri J. Development of the World Health Organization (WHO) community periodontal index of treatment needs (CPITN). Int Dent J 1982;32:281-91.

4. Axelsson P, Lindhe J, Nystron B. Prevention of caries and periodontal disease. Results of a 15-year longitudinal study in adults. J Clin Periodontol 1991;18:182-9.

5. Barkvoll P, Rolla G, Svendsen K. Interaction between chlorhexidine digluconate and sodium lauryl sulphate in vivo. J Clin Periodontol 1989;16:593-5.

6. Binney A, Addy M, Owens J, Faulkner J, McKeown S, Everatt L. A 3-month home use study comparing the oral hygiene and gingival health benefits of triclosan and conventional fluoride toothpastes. J Clin Periodontol 1996;23:1020-4.

7. Brecx M, Netuschil L, Reichert B, Schreil G. Efficacy of Listerine, Meridol, and chlorhexidine mouthrinses on plaque, gingivitis and plaque bacteria vitality. J Clin Periodontol 1990; 17:292-7.

8. Caton JG, Blieden TM, Lowenguth R, Frantz BJ, Wagener $\mathrm{CJ}$, Doblin JM, et al. Comparison between mechanical cleansing and an antimicrobial rinse for the treatment
0 (plaque-free surfaces) from $12 \%$ at baseline to $35 \%$ at the end of the trial, and a mean reduction in GI from 1.3 to 1.1 .

Our results showed that there was no additional benefit of the test dentifrice over the positive control toothpaste $\left(\right.$ Colgate Tota $\left.{ }^{\circledR}\right)$. Nevertheless, these results don't mean that the test dentifrice has not been efficient. The Parodontax ${ }^{\circledR}$ group showed a significant decrease in Plaque Index and in the Gingival index. The reductions in both indices were significant when compared to baseline values. Moreover, the product was compared with a dentifrice containing triclosan, which is an antimicrobial agent whose safety and efficacy have been well established ${ }^{9}$. It can be inferred, by our results, that the herbal dentifrice was as efficacious as the one with triclosan, and may be an alternative for people interested in natural products.

\section{CONCLUSION}

The authors conclude that both dentifrices were able to reduce plaque and gingivitis, although no additional benefit of the test dentifrice over the positive control toothpaste could be observed.

and prevention of interdental gingivitis. $\mathrm{J}$ Clin Periodontol 1993;20:172-8.

9. Davies RM, Ellwood RP, Davies GM. The effectiveness of a toothpaste containing triclosan and polyvinyl-methyl ether maleic acid copolymer in improving plaque control and gingival health. A systematic review. J Clin Periodontol 2004;31:1029-33.

10. Kornman KS. The role of supragingival plaque in the prevention and treatment of periodontal disease. J Periodontal Res 1986;21:5-22.

11. Lindhe J, Koch G. The effect of supervised oral hygiene on the gingiva of children. Lack of prolonged effect of supervision. J Periodontal Res 1967;2:215-22.

12. Lindhe J, Rosling B, Socransky SS, Volpe AR. The effect of a triclosan containing dentifrice on established plaque and gingivitis. J Clin Periodontol 1993;20:327-34.

13. Löe H, Silness J. Periodontal disease in pregnancy. Acta Odontol Scand 1963;21:533-51.

14. Löe H, Theilade E, Jensen SB. Experimental gingivitis in man. J Periodontol 1965;36:177-87.

15. Moran J, Addy M, Newcombe RG, Marlow I. A study to assess the plaque inhibitory action of a newly formulated triclosan toothpaste. J Clin Periodontol 2001;28:86-9.

16. Mullaly BH, James JA, Coulter WA, Linden GJ. The efficacy of a herbal based toothpaste on the control of plaque and gingivitis. J Clin Periodontol 1995;22:685-9.

17. Owens J, Addy M, Faulkner J. An 18 week home-use study comparing the oral hygiene and gingival benefits 
Ozaki F, Pannuti CM, Imbronito AV, Pessotti W, Saraiva L, Freitas NM, Ferrari G, Cabral VN. Efficacy of a herbal toothpaste on patients with established gingivitis - a randomized controlled trial. Braz Oral Res 2006;20(2):172-7.

of triclosan and fluoride toothpastes. J Clin Periodontol 1997;24:626-31.

18. Pannuti CM, Mattos JP, Ranoya PN, Jesus AM, Romito GA, Lotufo RFM. Clinical effect of a herbal dentifrice on the control of plaque and gingivitis. Pesq Odontol Bras 2003;17:314-8.

19. Quigley GA, Hein JW. Comparative cleansing efficiency of manual and power brushing. J Am Dent Assoc 1962;25:26-9.

20. Saxer UP, Menghini G. The effect of two toothpastes on plaque and gingival inflammation. J Clin Dent 1995;6:1546.

21. Triratana T, Rustogi KN, Volpe AR, DeVizio W, Petrone M, Giniger M. Clinical effect of a new liquid dentifrice containing triclosan/copolymer on existing plaque and gingivitis. J Am Dent Assoc 2002;133:219-25.

22. Triratana T, Tuongratanaphan S, Kraivaphan P, Rustogi KN, Volpe AR. The effect on established plaque formation and gingivitis of a triclosan/copolymer/fluoride dentifrice. A six month study. J Dent Assoc Thai 1993;43:19-28.

23. Turesky S, Gilmore ND, Glickman I. Reduced plaque formation by the chloromethyl analogue of victamine C. J Periodontol 1970;41:41-3.

24. Yankell SL, Emling RC. Two-month evaluation of Parodontax dentifrice. J Clin Dent 1988;1:22-4.

25. Yankell SL, Emling RC, Perez B. Six-month evaluation of Parodontax dentifrice compared to a placebo dentifrice. J Clin Dent 1993;4:26-30.

Received for publication on Sep 21, 2005

Sent for alterations on Mar 08, 2006

Accepted for publication on Apr 28, 2006 